\title{
Comparison of a nurse initiated insulin infusion protocol for intensive insulin therapy between adult surgical trauma, medical and coronary care intensive care patients
}

\author{
Melissa M Barth*1, Lance J Oyen ${ }^{2}$, Karen T Warfield ${ }^{1}$, Jennifer L Elmer ${ }^{1}$, \\ Laura K Evenson ${ }^{1}$, Ann N Tescher ${ }^{1}$, Philip J Kuper ${ }^{2}$, Michael P Bannon ${ }^{3}$, \\ Ognjen Gajic ${ }^{4}$ and J Christopher Farmer ${ }^{4}$
}

\begin{abstract}
Address: ${ }^{1}$ Department of Nursing, Mayo Clinic, Rochester, Minnesota, USA, ${ }^{2}$ Pharmacy Services, Mayo Clinic, Rochester, Minnesota, USA, ${ }^{3}$ Department of Surgery, Mayo Clinic, Rochester, Minnesota, USA and ${ }^{4}$ Department of Medicine, Mayo Clinic, Rochester, Minnesota, USA

Email: Melissa M Barth* - barth.melissa@mayo.edu; Lance J Oyen - oyen.lance@mayo.edu; Karen T Warfield - warfield.karen@mayo.edu; Jennifer L Elmer - elmer.jennifer@mayo.edu; Laura K Evenson - evenson.laura@mayo.edu; Ann N Tescher - tescher.ann@mayo.edu; Philip J Kuper - kuper.philip@mayo.edu; Michael P Bannon - bannon.michael@mayo.edu; Ognjen Gajic - gajic.ognjen@mayo.edu; J Christopher Farmer - farmer.j@mayo.edu

* Corresponding author
\end{abstract}

Published: 29 August 2007

BMC Emergency Medicine 2007, 7:14 doi:10.1186/1471-227X-7-14

This article is available from: http://www.biomedcentral.com/I47/-227X/7//4

(c) 2007 Barth et al; licensee BioMed Central Ltd.

This is an Open Access article distributed under the terms of the Creative Commons Attribution License (http://creativecommons.org/licenses/by/2.0), which permits unrestricted use, distribution, and reproduction in any medium, provided the original work is properly cited.
Received: 19 January 2007

Accepted: 29 August 2007

\begin{abstract}
Background: Sustained hyperglycemia is a known risk factor for adverse outcomes in critically ill patients. The specific aim was to determine if a nurse initiated insulin infusion protocol (IIP) was effective in maintaining blood glucose values (BG) within a target goal of $100-150 \mathrm{mg} / \mathrm{dL}$ across different intensive care units (ICUs) and to describe glycemic control during the 48 hours after protocol discontinuation.

Methods: A descriptive, retrospective review of 366 patients having 28, 192 blood glucose values in three intensive care units, Surgical Trauma Intensive Care Unit (STICU), Medical (MICU) and Coronary Care Unit $(C C U)$ in a quaternary care hospital was conducted. Patients were > 15 years of age, admitted to STICU ( $n=162)$, MICU ( $n=110)$ or CCU $(n=94)$ over 8 months; October 2003-June 2004 and who had an initial blood glucose level > $150 \mathrm{mg} / \mathrm{dL}$. We summarized the effectiveness and safety of a nurse initiated IIP, and compared these endpoints among STICU, MICU and CCU patients.

Results: The median blood glucose values $(\mathrm{mg} / \mathrm{dL})$ at initiation of insulin infusion protocol were lower in STICU (I88; IQR, I 62-2 I7) than in MICU, (20I; IQR, I70-268) and CCU (227; IQR, I78-3 I3); $p<0.000$ I. Mean time to achieving a target glucose level $(100-150 \mathrm{mg} / \mathrm{dL})$ was similar between the three units: 4.6 hours in STICU, 4.7 hours in MICU and 4.9 hours in CCU $(p=0.27)$. Hypoglycemia $(B G<60 \mathrm{mg} / \mathrm{dL})$ occurred in $7 \%$ of STICU, $5 \%$ of MICU, and $5 \%$ of CCU patients $(p=0.85)$. Protocol violations were uncommon in all three ICUs. Mean blood glucose 48 hours following IIP discontinuation was significantly different for each population: $142 \mathrm{mg} / \mathrm{dL}$ in STICU, $167 \mathrm{mg} / \mathrm{dL}$ in MICU, and $160 \mathrm{mg} / \mathrm{dL}$ in CCU $(p<$ $0.0001)$.

Conclusion: The safety and effectiveness of nurse initiated IIP was similar across different ICUs in our hospital. Marked variability in glucose control after the protocol discontinuation suggests the need for further research regarding glucose control in patients transitioning out of the ICU.
\end{abstract}




\section{Background}

Sustained hyperglycemia is a known risk factor for adverse outcomes in the critically ill patient, whether or not the patient has a history of diabetes mellitus [1-3]. There are many factors that affect glycemic control; metabolic derangement and counter-regulation, increased stress, decrease insulin (resistance or underproduction), increased glucose administration just to name a few $[4,5]$. Although short term glycemic increases related to stress are not associated with rise in mortality in all populations $[1,6,7]$.

Intensive insulin therapy is emerging as a treatment modality. At the time of our study, other than cardiovascular surgery patients $[1,8,9]$, it was uncertain what specific patient populations benefit from intensive insulin therapy. Other populations are beginning to emerge in the literature [7]; trauma patients [10,11], intraoperative [12], and medical patients $[13,14]$.

Despite some uncertainties, the management of hyperglycemia utilizing insulin protocols is fast becoming a new standard in critical care practice [1,13-23]. Nurse initiated protocols generally have been found to improve patient care $[13,17,22]$, limit the prescribing variability $[15,16,18,20,24]$ and contribute to financial cost savings [17]. However it is unknown if a nurse initiated IIP is effective and safe across different ICU populations. Also, it appears similar protocols in different populations' yields different clinical outcomes $[9,14]$. It is unclear if the protocol or operation of the protocol leads in part to these differences.
In this study we sought to determine if the IIP was effective and safe in bringing blood glucose values within the target range of $100-150 \mathrm{mg} / \mathrm{dL}$ among the three different ICUs (surgical, medical and coronary care). We were also interested in glycemic control across different ICU populations in the first 48 hours after the IIP was discontinued, when the patients transition out of the ICU.

\section{Methods \\ Design}

We conducted a descriptive retrospective review of 366 patients having 28,192 blood glucose values in the analysis of outcomes after Mayo Foundation Institutional Review Board (IRB) approval was granted. Patients had been cared for in one of three ICUs in a quaternary care hospital at Mayo Clinic Rochester, MN where an intensive insulin protocol was utilized. The ICUs included a 24-bed Surgical Trauma Intensive Care Unit (STICU), a 24-bed Medical ICU (MICU), and a 16-bed Coronary Care Unit (CCU).

\section{Patients}

Inclusion criteria included adult patients, 15 years of age and older, admitted to STICU, MICU or CCU who had a blood glucose level greater than $150 \mathrm{mg} / \mathrm{dL}$ while on the unit and were placed on an IIP during the identified data collection time frame October 2003-June 2004. 366 out of 386 eligible patients were used for data analysis. Eighteen patients were excluded since they did not grant approval for use of their data for research purposes. One patient was not started on insulin drip and one was on a modified insulin drip prior to ICU admission. There were not any other exclusion criteria. Patients readmitted to the ICU during the same or subsequent hospitalization were

Table I: Patient characteristics

\begin{tabular}{|c|c|c|c|c|}
\hline & STICU $(n=162)$ & $\operatorname{MICU}(n=1 \mid 0)$ & $\operatorname{CCU}(n=94)$ & $p$ Value \\
\hline Age, mean (SD) & $59.9(19.5)$ & $61.4(17.6)$ & $67.8(12.7)$ & 0.01 \\
\hline Gender, Female, n (\%) & 79 (49) & $57(52)$ & $35(37)$ & 0.09 \\
\hline Weight, kg, mean (SD) & $90.5(32.9)$ & $84.7(25.8)$ & $87.4(23.0)$ & 0.70 \\
\hline Height, cm, mean (SD) & $169.0(9.6)$ & $167.4(19.4)$ & $170.5(10.2)$ & 0.44 \\
\hline Diabetes, n (\%) & $48(30)$ & $47(43)$ & $57(61)$ & $<0.0001$ \\
\hline \multicolumn{5}{|l|}{ Medications } \\
\hline $\begin{array}{l}\text { IV/Oral } \\
\text { Corticosteroids, n (\%) }\end{array}$ & $34(2 I)$ & $51(46)$ & $9(10)$ & $<0.0001$ \\
\hline $\begin{array}{l}\text { Epinephrine/ } \\
\text { Norepinephrine, n (\%) }\end{array}$ & $13(8)$ & $16(15)$ & $14(15)$ & 0.14 \\
\hline Beta blockers, n (\%) & $57(35)$ & $25(23)$ & $52(55)$ & $<0.0001$ \\
\hline $\begin{array}{l}\text { APACHE III score, mean } \\
\text { (SD) }\end{array}$ & $\begin{array}{c}\mathrm{n}=158 \\
52.7(21.9)\end{array}$ & $\begin{array}{l}n=109 \\
67.3(30.1)\end{array}$ & $\mathrm{n} / \mathrm{a}$ & $<0.0001$ \\
\hline $\begin{array}{l}\text { ICU LOS, days, median } \\
\text { (IQR) }\end{array}$ & $6.4(3.3-13.2)$ & $2.9(1.3-8.7)$ & $2.4(1.3-4.2)$ & $<0.001$ \\
\hline ICU mortality, n (\%) & $8(5)$ & $16(15)$ & $15(16)$ & 0.004 \\
\hline Hospital mortality, n (\%) & $12(7)$ & $21(19)$ & $25(27)$ & $<0.001$ \\
\hline
\end{tabular}

ICU, Intensive Care Unit; STICU, Surgical Trauma ICU; MICU, Medical ICU; CCU, Coronary Care Unit; APACHE, Acute Physiological and Chronic Health Evaluation; n/a, not available; LOS, length of stay; IQR, interquartile range 
not considered for analysis. Patient characteristics are summarized in Table 1.

\section{Interventions}

Intensive Insulin Infusion Protocol for Insulin Therapy

A 4-column, non-calculated protocol for continuous intravenous insulin administration (measured in units/ hour) on adult patients was initiated by the $\mathrm{RN}$ with blood glucose value greater than $150 \mathrm{mg} / \mathrm{dL}$ [see Additional file 1].

\section{Glucose Meter for Blood Sampling}

Blood glucose values collected by vascular access team (VAT) laboratory personnel, obtained by capillary "fingerstick", arterial or venous blood draw (measured in $\mathrm{mg} / \mathrm{dL}$ ) were measured via one of three methods: 1) Bedside glucose values were measured using a standard hospital glucose meter (SureStep Flexx; Lifescan, Johnson \& Johnson, New Brunswick, NJ). 2) Serum glucose values were measured using a standard hospital glucose instrument (Modular Roche Hitachi, Japan, Roche Corporation, Indianapolis, IN). 3) Plasma glucose values were measured using a standard hospital glucose instrument (Beckman Glucose Analyzer 2, Beckman Coulter, Brea, CA). It is estimated that $80 \%$ of blood glucose values were obtained by capillary, $19 \%$ by arterial and $1 \%$ by venous blood draw.

\section{Definitions}

Time to achieve goal: hours until first blood glucose value $\leq$ $150 \mathrm{mg} / \mathrm{dL}$

Safety: percent of blood glucose values $\geq 60 \mathrm{mg} / \mathrm{dL}$

Hyperglycemic: blood glucose $>150 \mathrm{mg} / \mathrm{dL}$

Hypoglycemic: blood glucose $<60 \mathrm{mg} / \mathrm{dL}$

Mean Percent: Reflects the average per-patient percent of blood glucose values meeting a specified criterion (e.g. values $>150$ or $<60 \mathrm{mg} / \mathrm{dL}$, falling outside the target IIP range), computed from the data from all individuals in the group of interest. To compute this value, the total number of blood glucose values meeting the criterion for a given patient were summed up, divided by the total number of blood glucose measurements, and multiplied by 100 . The mean percent was then computed as the simple average of the per-patient percentages for all subjects in the group of interest. This measure was used to reflect the total proportion of the time that study participants had blood glucose measurements outside the targeted IIP range.

\section{Procedure}

At our institution, following the publication of the Van den Berghe study [1], a group of nurses and pharmacists began exploring a project to examine if use of the IIP would make a difference in patient populations other than cardiovascular surgery. A recent pilot study was done on two cardiovascular surgery ICUs utilizing the RN initiated IIP which they adapted from a published protocol [15]. STICU, MICU and CCU ICU populations were utilized to determine if IIP would work similarly in different patient populations. Input and feedback were gathered related to management of patients on insulin. Collaboration with RNs, physicians \& pharmacists identified need for better control of critically ill patient blood glucose levels and support was obtained from physician leadership of each ICU. Since the IIP was a new protocol being utilized in STICU, MICU and CCU, staff registered nurses (RNs) were educated prior to implementation. Data collection began one month after education.

A target goal range of 100-150 mg/dL was established for our institutions IIP. Caution to avoid hypoglycemia was one factor that contributed to this range. This factor has been documented in the literature for other institutions as well. Total elimination of hypoglycemia is a desirable but difficult to achieve expectation of critically ill patients due to the confounding factors that contribute to their illness. Our institution has a hypoglycemic protocol to treat patients whose blood glucose falls below $60 \mathrm{mg} / \mathrm{dL}$.

Frequency of blood glucose measurements was determined by the IIP. Hourly values were obtained until the patient was in goal range for 4 continuous hours, and then the frequency was decreased to every two hours. Return to hourly monitoring occurred with the following identified situations: change in nutritional or clinical status, blood glucose above goal range for 2 consecutive readings or blood glucose below $100 \mathrm{mg} / \mathrm{dL}$.

Additional investigator developed tools utilized for data collection included an IIP Data Collection Tool (completed by the staff RN) and an IIP Clinical Nurse Specialist (CNS)/ Nursing Education Specialist (NES) Data Collection Tool which was completed after the protocol was discontinued. The IIP was discontinued at the time the patient transferred out to a general care floor, when ICU care was no longer deemed necessary. One investigator was present on each unit at least 5 days of the week to answer questions \& clarify use of protocol during the data collection period. Generally, in the 48 hours after protocol discontinuation, blood glucose monitoring continued at a lower frequency (2-4 times daily) based on glucose values, clinical situations or symptoms. There was variability in treatment ranging from higher goal insulin infusion (not IIP), subcutaneous insulin regimens, oral diabetic agents, or no 


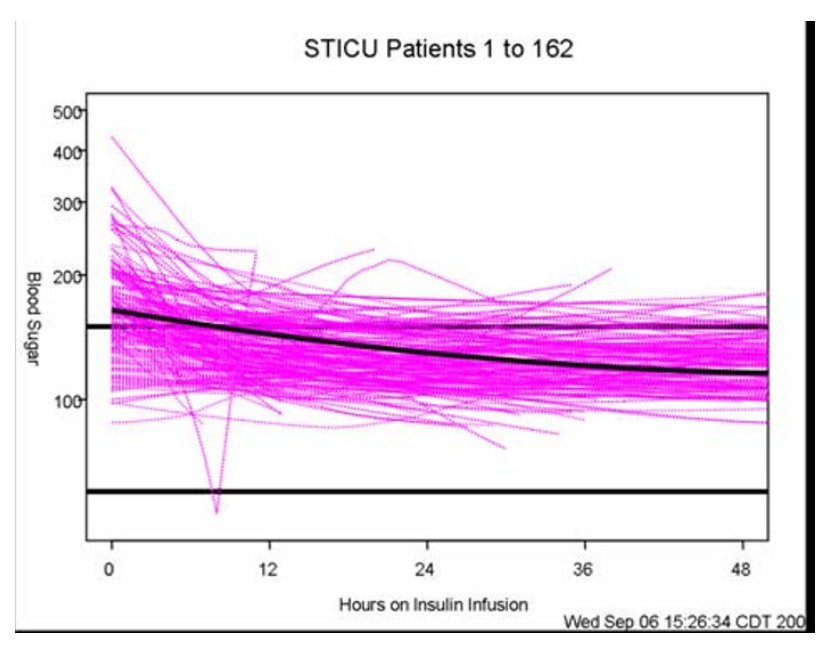

\section{Figure I}

Individual profiles of blood glucose of patients who underwent insulin infusion-STICU. Individual profiles of blood glucose of patients who underwent insulin infusion after admission to the STICU, $n=162$ (fuchsia lines) along with the predicted level of blood glucose (solid line). The predicted level of blood glucose is based on the mathematical model below where time is measured in days since the start of insulin infusion: Blood glucose $(\mathrm{mg} / \mathrm{dL})=\exp (5.1030$ $0.3023 *$ time $+0.0640 *$ time $*$ time) .

treatment. Patient follow-up was determined by the primary physician service.

\section{Statistical analysis}

Summary patient features, reported in Table 1 , were calculated for each of the three care units using means (standard deviations), or median (interquartile range) or count (percentage) as appropriate for the data. These variables were compared among the three units using chi-square tests for categorical data, and Kruskal-Wallis tests for continuous data. Comparisons of blood glucose decline among the units are shown by the profile plots in Figures $1,2,3$. These figures were generated using a mixed model analysis of variance. Specifically, the blood glucose level was modeled as a quadratic function of time (days) on insulin infusion taking into account the type of ICU and the serial aspect of the data. All blood glucose measurements from 2 hours prior to drip start until the order discontinuation time was used for data modeling. To decrease the influence of patients with prolonged ICU stay, any patient who underwent insulin infusion for more than 100 hours had their last measure truncated at 100 hours. As within patient blood glucose measurements could decrease over a wide range, say from $400 \mathrm{mg}$ to 100 $\mathrm{mg}$; a natural logarithm transformation to stabilize the variability of blood glucose was employed. The fitted data was examined for a quadratic association with time by inspecting the graphs which indicated that a quadratic association with time provided a reasonable fit to the data. The final model includes linear and quadratic terms for time, and an indicator variable for ICU type and the interactions between time and ICU type. Thus, the resulting models are multiplicative and curvilinear, meaning that a day on infusion results in a percent decrease in blood glucose but the decrease changes over days. Measurements of blood glucose which were made repeatedly over time were summarized by calculating the patients' mean blood glucose, during a specific interval, and calculating a series of box plots for each unit (Figures 4, 5, 6). The box plots indicate the distribution of the individual patient means. In addition to examining data collected during the IIP, measures of blood glucose obtained in the 48 hours following IIP were obtained, summarized and compared among units in the same manner as described for the data collected during the use of the IIP. The SAS statistical software (SAS Institute Inc, Cary NC) was used for all analyses, and two-sided $p$ values $<0.05$ were considered to be statistically significant.

\section{Results}

Three hundred and sixty-six patients met inclusion criteria over the eight months of the study period, 162 in STICU, 110 in MICU and 94 in the CCU. General patient characteristics are listed in Table 1. The average length of ICU stay, and the duration of IIP infusion varied, with STICU being the longest. The number of blood glucose measurements obtained while on the IIP compared to the 48 hours after IIP discontinuation were 13,120 (average 81 per patient)/1,926 in STICU, 6,639 (60 per patient)/1,322 in MICU, and 4,199/986 (45 per patient) in CCU. The total blood glucose values utilized for analysis was 28,192 . The median blood glucose values at initiation of IIP were statistically different for each unit, STICU, MICU, and CCU (Table 2). Mean insulin infusion rates, however, were similar in all 3 units. While we observed small differences in the time-response curves and individual blood glucose readings at the 24 hour time point, the overall safety and efficacy of the protocol were similar in all three ICUs (Table 2, Figures 1, 2, 3, 4, 5, 6). Deviations from the protocol were uncommon and similar across the 3 ICUs (Table 3).

A large percentage of patients in each of the ICUs experienced hyperglycemia after the IIP was discontinued and the patient transitioned out of the ICU. Table 4 summarizes the results 48 hours after the IIP discontinuation.

\section{Discussion}

To our knowledge, this is one of the first studies to compare use of a non-calculating insulin infusion protocol in 


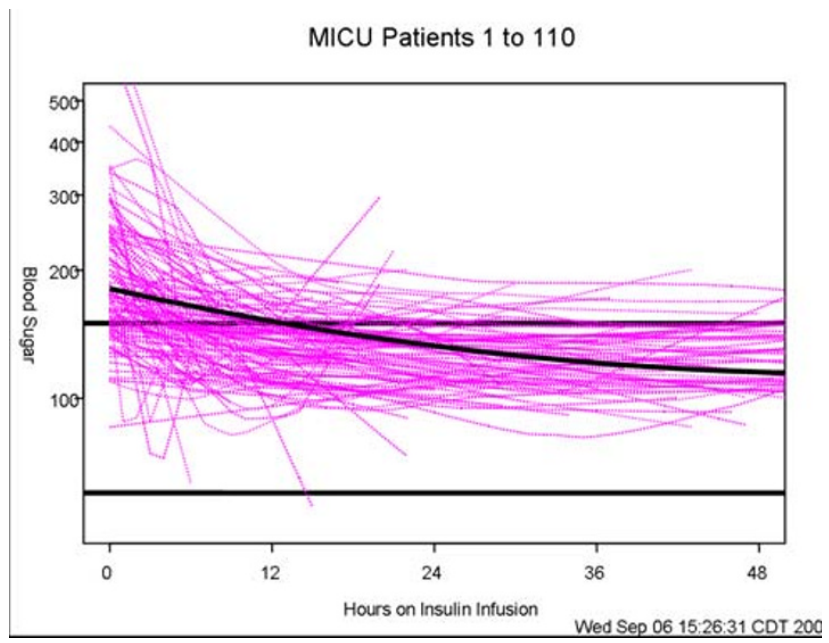

Figure 2

Individual profiles of blood glucose of patients who underwent insulin infusion-MICU. Individual profiles of blood glucose of patients who underwent insulin infusion after admission to the MICU, $\mathrm{n}=\mathrm{I} I 0$ (fuchsia lines) along with the predicted level of blood glucose (solid line). The predicted level of blood glucose is based on the mathematical model below where time is measured in days since the start of insulin infusion: Blood glucose $(\mathrm{mg} / \mathrm{dL})=\exp (5.1977$ $0.3936 *$ time $+0.0840 *$ time $*$ time $)$.

three different adult ICU patient populations. At the initiation of the protocol, hyperglycemia was more severe in medical than in surgical ICU patients. The protocol effectiveness and safety were, however, similar across the three

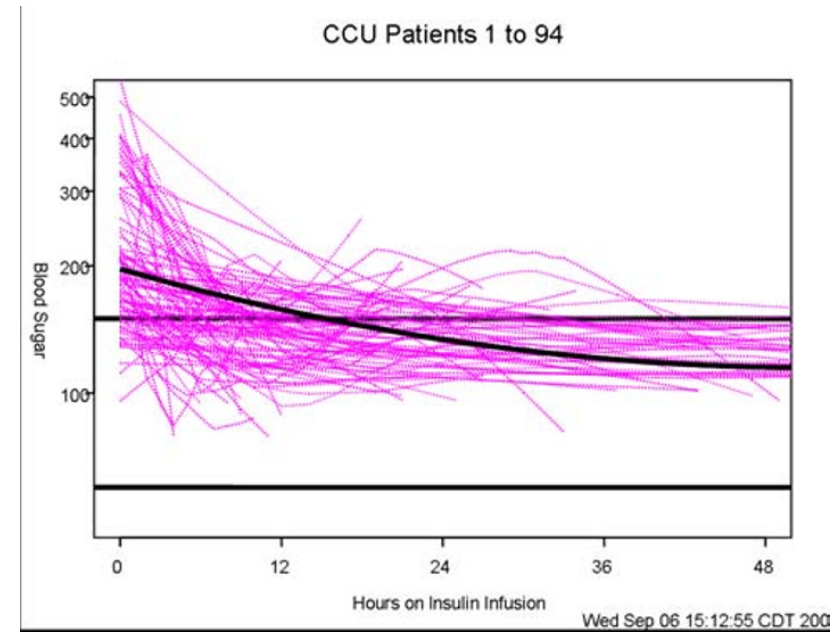

Figure 3

Individual profiles of blood glucose of patients who underwent insulin infusion-CCU. Individual profiles of blood glucose of patients who underwent insulin infusion after admission to the $\mathrm{CCU}, \mathrm{n}=94$ (fuchsia lines) along with the predicted level of blood glucose (solid line). The predicted level of blood glucose is based on the mathematical model below where time is measured in days since the start of insulin infusion: Blood glucose $(\mathrm{mg} / \mathrm{dL})=\exp (5.2808-$ $0.4987 *$ time $+0.1160 *$ time $*$ time $)$.

ICUs. A large percentage of patients developed hyperglycemia after IIP discontinuation.

Table 2: Summary data while on the insulin infusion protocol

\begin{tabular}{|c|c|c|c|c|}
\hline & $\operatorname{STICU}(n=162)$ & $\operatorname{MICU}(n=110)$ & $\operatorname{CCU}(n=94)$ & $p$ Value \\
\hline $\begin{array}{l}\text { Blood glucose at initiation } \\
\text { of IIP, median (IQR), } \mathrm{mg} / \mathrm{dL}\end{array}$ & $188(162-217)$ & $201(170-268)$ & $227(|78-3| 3)$ & $<.0001$ \\
\hline $\begin{array}{l}\text { Insulin infusion rates, mean } \\
(\mathrm{SE})^{*}, \mathrm{ml} / \mathrm{hr}\end{array}$ & $1.7(0.10)$ & $1.7(0.12)$ & $2.0(0.13)$ & 0.19 \\
\hline $\begin{array}{l}\text { Hours until BG } \leq 150 \mathrm{mg} / \\
\mathrm{dL} \text {, mean (SD) }\end{array}$ & $\begin{array}{l}n=159 \\
4.6(4.4)\end{array}$ & $\begin{array}{l}\mathrm{n}=103 \\
4.7(4.4)\end{array}$ & $\begin{array}{c}n=89 \\
4.9(3.9)\end{array}$ & 0.27 \\
\hline \multicolumn{5}{|l|}{$\begin{array}{l}\text { Patients > } 150 \mathrm{mg} / \mathrm{dL} @ \\
\text { time point, n (\%): }\end{array}$} \\
\hline $12 \pm 2$ hours & $37 / 158(23)$ & 28/96 (29) & $24 / 82$ (29) & 0.49 \\
\hline $24 \pm 2$ hours & $18 / 138(13)$ & $13 / 77$ (17) & $20 / 56(36)$ & 0.001 \\
\hline $36 \pm 2$ hours & $19 / 117(16)$ & $12 / 60(20)$ & $9 / 40(23)$ & 0.63 \\
\hline $48 \pm 2$ hours & $15 / 104(14)$ & $12 / 44(27)$ & $6 / 29(21)$ & 0.18 \\
\hline $\begin{array}{l}\text { Duration IIP use, days, } \\
\text { mean (SD) }\end{array}$ & $3.8(3.8)$ & $2.8(2.7)$ & $2.0(2.5)$ & $<0.0001$ \\
\hline $\begin{array}{l}\text { Patients with at least one } \\
\text { blood glucose }<60 \mathrm{mg} / \mathrm{dL} \text {, } \\
\mathrm{n}(\%)\end{array}$ & II (7) & $6(5)$ & $5(5)$ & 0.85 \\
\hline $\begin{array}{l}\text { Mean percent } B G<60 \mathrm{mg} / \\
\mathrm{dL} \text {, mean (SD) }\end{array}$ & $0.2(1.4)$ & $0.3(1.5)$ & $0.1(0.6)$ & 0.88 \\
\hline
\end{tabular}

IQR, interquartile range; $B G$, blood glucose; SE, standard error

*To account for multiple values measured per person 
STICU Patients

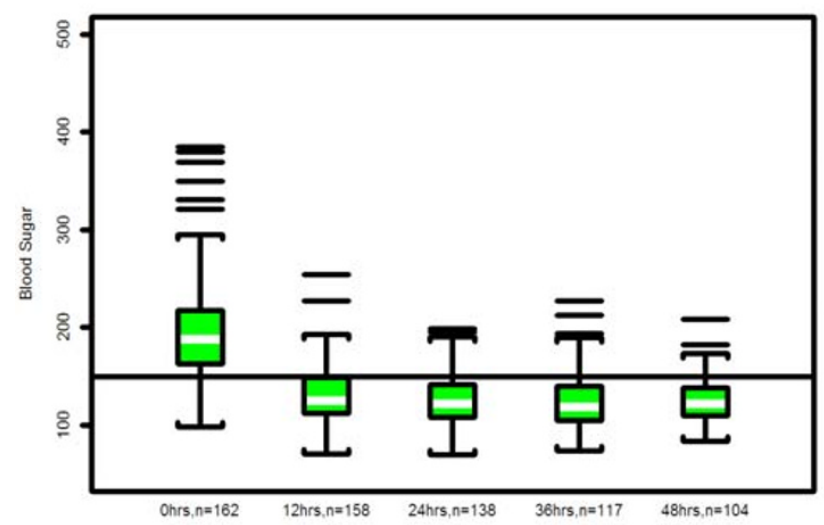

Figure 4

Median \& interquartile range of actual blood glucose values of patients who underwent insulin infusion after admission-STICU. The box plots indicate the distribution of the individual patient means. See statistical methods section for details.

In our study, hyperglycemia in medical patients may be attributed to a higher incidence of diabetes in CCU \& MICU as compared to STICU. In addition, there was higher use of IV or oral corticosteroids in MICU and beta blocker use in CCU. However, despite different starting blood glucose values, the finding of mean time (hours) that the patients blood glucose value first dropped to < $150 \mathrm{mg} / \mathrm{dL}$ was similar in all three units (STICU 4.6, MICU 4.7, CCU 4.9; $p=0.27$ ) is meaningful. This suggests that even though the patients were located in different ICUs (thus presuming different diagnoses); their response to the same IIP was effective. Interestingly, the only difference in patient blood glucose $>150 \mathrm{mg} / \mathrm{dL}$ was found at 24 hours between STICU (13\%), MICU (17\%), and CCU $(36 \%) ; p<0.001$. Although statistically significant, this may not be clinically significant given that approximately half of the CCU patients were not on the IIP at 24 hours. Between patient variability is indicated by the width of the box plots show in Figures 4, 5, 6. For MICU (Figure 5) and CCU (Figure 6) patients, time 0 blood glucose is highly variable but decreases over time. STICU (Figure 4)

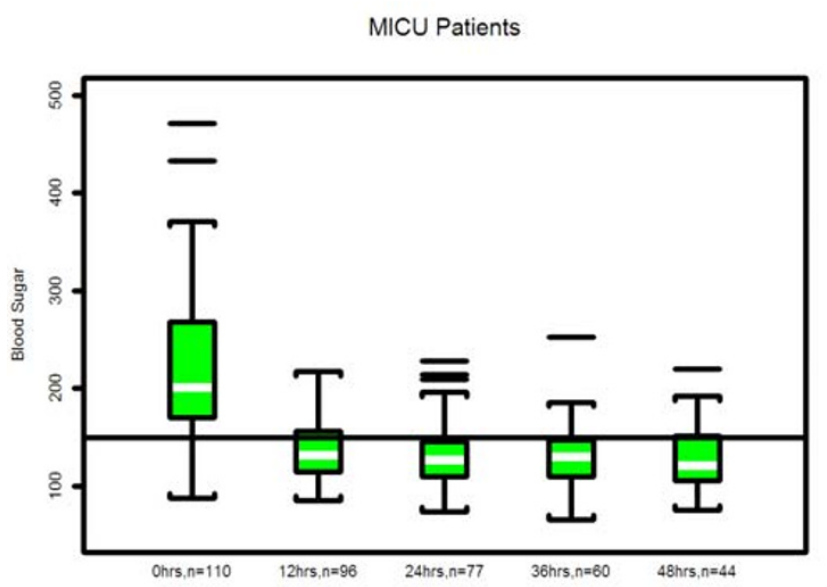

Figure 5

Median \& interquartile range of actual blood glucose values of patients who underwent insulin infusion after admission-MICU. The box plots indicate the distribution of the individual patient means. See statistical methods section for details.

patients are not as variable at time 0 and have less decrease over time.

Furthermore, mean insulin drip rates, time to goal, and deviation from IIP all were clinically similar and not statistically significant which may suggest that patient differences, not protocol adherence, may be the contributing factor that may account for our findings. Although we did not look for absolute deviations, we cannot rule these out. We also acknowledge the potential that investigators could have biased the outcome related to deviations due to presence on the unit. It appears that in critically ill patients, glucose levels rather than amount of insulin infused account for mortality benefit [25]. The Van den Berghe study [1] found reductions in mortality and morbidities attributable to mean glucose of $103 \mathrm{mg} / \mathrm{dl}$ in the intensive treatment group compared to the more modestly treated group with mean glucose value of $153 \mathrm{mg} / \mathrm{dL}$. Furthermore, the findings appeared most dramatic in the patients who had ICU stays of greater than 5 days. Limitations of Van den Berghe's study include questionable gen-

Table 3: Deviations from insulin infusion protocol

\begin{tabular}{lccc} 
& STICU $(\mathbf{n}=1 \mathbf{6 2})$ & MICU (n= I I0) & CCU (n= 94) \\
\hline Started in a wrong column & 27 & 15 & 15 \\
Jumped a column & 0 & 0 & 1 \\
BG $<150 \mathrm{mg} / \mathrm{dL}$ when IIP started & 4 & 2 & 1 \\
Patients with deviation, $\mathrm{n}(\%)$ & $31(19)$ & $17(15)$ & $17(18)$ \\
\hline
\end{tabular}

BG, blood glucose 


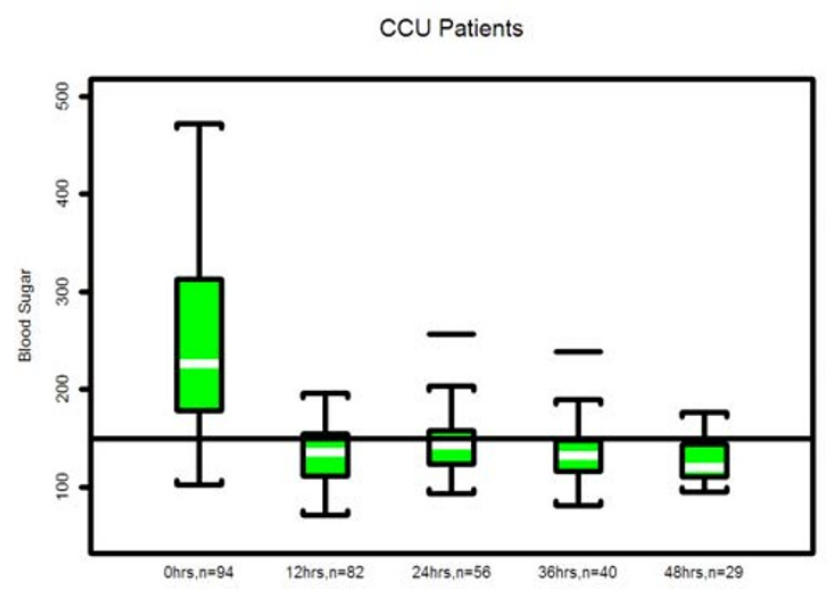

Figure 6

Median \& interquartile range of actual blood glucose values of patients who underwent insulin infusion after admission-CCU. The box plots indicate the distribution of the individual patient means. See statistical methods section for details.

eralizability of results outside of the cardiac surgical population, single center study with unclear feasibility in a larger scope, and early aggressive glucose administration for all patients in both treatment and control groups which may have forced some of the hyperglycemia and insulin dosing. However, the study has largely been embraced as evidence for intensive insulin therapy in the ICU.

Our patient characteristics do show a difference between age, diabetes, steroid, and beta blocker use which may contribute to each ICUs difference in blood glucose value at initiation of IIP. Moreover, ICU length of stay and IIP duration was greater in the STICU compared to MICU and CCU. Because of this time difference, comparing mean blood glucose values was not pertinent because of the correlation to length on the IIP (the longer on the IIP, the great chance to get into goal range). Hyperglycemia was a risk factor in non diabetic patients admitted in cardiac, cardiothoracic and neurosurgical ICUs, however not in medical or general surgical ICUs [7]. In addition, intraoperative hyperglycemia was found to be an independent risk factor for complications following cardiac surgery [12]. Although a recent study [14] revealed insulin therapy has been shown to reduce morbidity in medical ICU patients. This lends the importance of examining different patient populations who may be at risk for hyperglycemia.

Most nurse initiated protocols identified thus far in the literature have a component where the $\mathrm{RN}$ needs to perform some method of calculation to derive the insulin rate to be infused [16-18,21,22]. The use of our non-calculated IIP in this study, contributes to the safety and standardization of the protocol. It appears our 4-column protocol adapts to glucose sensitive and resistant patients in a similar way in multiple patient populations. In addition, use of a nurse initiated IIP has significant impact on nursing practice by demonstrating decision making and critical thinking skills by the $\mathrm{RN}$ in the care of the critically ill patient.

The concern regarding the risk of hypoglycemia with intensive insulin protocols has limited the expansion to general care areas. However, the incidence of severe hypoglycemia ( $<40 \mathrm{mg} / \mathrm{dL}$ ) of patients on a protocol was similar in both critical care $(4 \%)$ and non-critical care (3.6\%) areas [20]. In addition, hypoglycemia ( $<45 \mathrm{mg} /$ $\mathrm{dL}$ ) was not associated with mortality, although noted to be a small study [26]. A systematic review of twenty-four reports suggest that tight glucose control protocols maintained adequate glycemic control and resulted in low frequencies of hypoglycemia [23]. Our study also had a more conservative definition of hypoglycemia $(<60 \mathrm{mg} / \mathrm{dL})$ with similar incidence across the 3 ICUs. Survivors within the 48 hours after IIP discontinuation or patient transfer, patients had significant increase in mean percent of blood glucose values $>150 \mathrm{mg} / \mathrm{dL}(p<0.0001)$. Given limited hypoglycemia risks and our results related to hyperglycemia after protocol discontinuation or patient transfer, it would seem prudent to research the use of IIP in general care areas and explore this transition further.

Table 4: Forty-eight hours after insulin infusion protocol discontinued or patient transfer

\begin{tabular}{|c|c|c|c|c|}
\hline & STICU (n = I49) & MICU $(n=99)$ & $\operatorname{CCU}(n=83)$ & p Value \\
\hline $\begin{array}{l}\text { Mean percent of BG > } 150 \\
\mathrm{mg} / \mathrm{dL} \text {, mean (SD) }\end{array}$ & $26(28)$ & $43(32)$ & $38(29)$ & $<0.0001$ \\
\hline \multirow{2}{*}{$\begin{array}{l}\text { BG measurements, mean } \\
\text { (SD) }\end{array}$} & $n=1926$ & $n=1322$ & $n=986$ & \\
\hline & $17.5(17.0)$ & $15.2(13.9)$ & $13.5(10.7)$ & 0.02 \\
\hline $\mathrm{BG}$, mean $(\mathrm{SE})^{*}, \mathrm{mg} / \mathrm{dL}$ & $142(3.6)$ & $167(4.4)$ & $160(4.8)$ & $<0.0001$ \\
\hline
\end{tabular}

BG, blood glucose; SE, standard error

*To account for multiple values measured per person 
The investigators acknowledge several limitations with this study. It was conducted in one setting with a lack of randomized, controlled design. There were patient differences between and within population groups that were not controlled for and a convenience sample of patients who met inclusion criteria was utilized. We acknowledge variability with utilizing three different types of blood glucose measurements. At the time of the study, common practice was to perform measurement with a capillary sample. Extreme values (BG $>400 \mathrm{mg} / \mathrm{dL}$ and $<60 \mathrm{mg} /$ $\mathrm{dL}$ ) were verified with an additional venous or arterial sample. We have subsequently changed to utilizing arterial samples, when arterial line is in place. We only use capillary blood glucose in occasions of no arterial line, based on ours and others analysis of variances in the extremes of glucose levels associated with capillary analysis [27]. In addition, there were different RNs implementing and following the protocol and the demographic and transfer data was collected by different data collectors. The lack of fidelity or integrity measures to assure nurses were implementing the interventions accurately and reliably is also recognized. Based on findings from this study related to IIP safety, current research literature, and input from physicians, pharmacists and nurses at our institution, a revised 3-column IIP with a tighter goal range for blood glucose levels of $80-130 \mathrm{mg} / \mathrm{dL}$ has been implemented and is available for use in any adult ICU. Although it is recognized that oversimplification of the initial 4-column approach may lead to differentiation of outcomes in different populations.

\section{Conclusion}

The RN initiated IIP was effective and safe in achieving a target glucose goal of $100-150 \mathrm{mg} / \mathrm{dL}$ in the surgical, cardiac and medical ICUs in our institution. The key to successful IIP use involved multidisciplinary team approach of nurses, pharmacists, physicians and laboratory personnel. No further tailoring of this protocol is needed for use amongst differing patient groups. Control of blood glucose post IIP had marked variability suggesting the need for further studies regarding protocolized glucose control of patients transitioning out of the ICU.

\section{Competing interests}

The author(s) declare that they have no competing interests.

\section{Authors' contributions}

$\mathrm{MB}$ conceived of the study, participated in its design, carried out the education of the protocol, participated in the data collection, entered some data for analysis, coordinated and drafted the manuscript. LO conceived of the study, participated in its design, and helped draft the manuscript. KW, JE, LE, AT, conceived of the study, participated in study design, carried out the education of the protocol, participated in the data collection and helped draft the manuscript. PK, MB, OG, JCF participated in study design and helped draft the manuscript. All authors read and approved the final manuscript.

\section{Additional material}

\section{Additional file 1}

Insulin Infusion Protocol. The image provided represents the insulin infusion protocol utilized for the study. By permission of Mayo Foundation for Medical Education and Research. All rights reserved.

Click here for file

[http://www.biomedcentral.com/content/supplementary/1471227X-7-14-S1.jpeg]

\section{Acknowledgements}

The authors would like to acknowledge Vernon S. (Shane) Pankratz, PhD, SAC and Michael Malinchoc, MS for statistical assistance. In addition, the cardiovascular surgery staff that adapted and implemented the initial pilot of IIP as well as the Staff RNs on the STICU, MICU and CCU for their time and effort to enter data on the data collection tools and VAT members who performed bedside glucose testing.

Statistics were supported by Institutional Department of Nursing and Critical Care Research Divisions funds.

\section{References}

I. Van den Berghe G, Wouter P, Weekers F, Verwaest C, Bruyninckx F, Schetz M, Vlasselaers D, Ferdinande P, Lauwers P, Bouillon R: Intensive insulin therapy in critically ill patients. N Engl J Med 200I, 345: $1359-1367$.

2. Capes SE, Hunt D, Malmberg K, Gersstein HC: Stress hyperglycaemia and increased risk of death after myocardial infarction in patients with and without diabetes: a systematic overview. Lancet 2000, 355:773-778.

3. Malmberg K, Norhammar A, Wedel H, Ryden L: Glycometabolic state at admission: important risk marker of mortality in conventionally treated patient with diabetes mellitus and acute myocardial infarction long -term results from the diabetes and insulin-glucose infusion in acute myocardial infarction (DIGAMI) study. Circulation 1999, 99:2626-2632.

4. Preiser JC, Devos P, Van den Berghe G: Tight control of glycaemia in critically ill patients. Curr Opin Clin Nutr Metab Care 2002, 5:533-537.

5. McCowen KC, Malhotra A, Bistrian BR: Stress-induced hyperglycemia. Crit Care Clin 200 I, I7:107-I24.

6. Friere AX, Bridges L, Umpierrez GE, Kuhl D, Kitabchi AE: Admission hyperglycemia and other risk factors as predictors of hospital mortality in a medical ICU population. Chest 2005, I 28:31093|16.

7. Whitcomb BW, Pradhan EK, Pittas AG, Roghmann MC, Perencevich EN: Impact of admission hyperglycemia on hospital mortality in various intensive care unit populations. Crit Care Med 2005, 33:2772-2777.

8. Pittas AG, Siegel RD, Lau J: Insulin therapy for critically ill hospitalized patients: A meta-analysis of randomized controlled trials. Arch Intern Med 2004, 164:2005-20II.

9. Van den Berghe G, Wouter PJ, Bouillon R, Weekers F, Verwaest C, Schetz M, Vlasselaers D, Ferdinande P, Lauwers P: Outcome benefit of intensive insulin therapy in the critically ill: Insulin dose versus glycemic control. Crit Care Med 2003, 31:359-366.

10. Laird AM, Miller PR, Kilgo PD, Meredith JW, Chang MC: Relationship of early hyperglycemia to mortality in trauma patients. J Trauma 2004, 56:1058-1062. 
II. Bochicchio GV, Sung J, Joshi M, Bochicchio K, Johnson SB, Meyer W, Scalea TM: Persistent hyperglycemia is predictive of outcome in critically ill trauma patients. J Trauma 2005, 58:92I-924.

12. Gandhi GY, Nuttall GA, Abel MD, Mullany C, Schaff HV, Williams BA, Schrader LM, Rizza RA, McMahon MM: Intraoperative hyperglycemia and perioperative outcomes in cardiac surgery patients. Mayo Clin Proc 2005, 80:862-866.

13. Krinsley JS: Effect of intensive glucose management protocol on the mortality of critically ill adult patients. Mayo Clin Proc 2004, 79:992-1000.

14. Van den Berghe G, Wilmer A, Hermans G, Meersseman W, Wouters PJ, Milants I, Van Wijngaerden E, Bobbaers H, Bouillon R: Intensive insulin therapy in the medical ICU. N Engl J Med 2006, 354:449-46I.

15. Markovitz LJ, Wiechmann RJ, Harris N, Hayden V, Cooper J, Johnson G, Harelstad R, Calkins L, Braithwaite SS: Description and evaluation of a glycemic management protocol for patients with diabetes undergoing heart surgery. Endocr Pract 2002, 8:10-18.

16. Laver S, Preston S, Turner D, McKinstry C, Padkin A: Implementing intensive insulin therapy: Development \& audit of the Bath insulin protocol. Anaesth Intensive Care 2004, 32:3 I I-3 I6.

17. Kanji S, Singh A, Tierney M, Meggison H, Mclntyre L, Hebert PC: Standardization of intravenous insulin therapy improves the efficiency and safety of blood glucose control in critically ill adults. Intensive Care Med 2004, 30:804-8I0.

18. Goldberg PA, Siegel MD, Sherwin RS, Halickman JI, Lee M, Bailey VA, Lee SL, Dziura JD, Inzucchi SE: Implementation of a safe and effective insulin infusion protocol in a medical intensive care unit. Diabetes Care 2004, 27:46I-467.

19. Dellinger RP, Carlet JM, Masur H, Gerlach H, Calandra T, Cohen J, Gea-Banacloche J, Keh D, Marshall JC, Parker MM, et al.: Surviving sepsis campaign guidelines for management of sever sepsis and septic shock. Crit Care Med 2004, 32:858-873.

20. Ku SY, Sayre CA, Hirch IB, Kelly IL: New insulin infusion protocol improves blood glucose control in hospitalized patients without increasing hypoglycemia. Jt Comm J Qual Saf 2005, 3I:I4I-I47.

21. Dilkhush D, Lannigan J, Pedroff T, Riddle A, Tittle M: Insulin infusion protocol for critical care units. Am J Health-Syst Pharm 2005, 62:2260-2264.

22. Taylor BE, Schallom ME, Sona CS, Buchman TG, Boyle WA, Mazuski JE, Schuerer DE, Thomas JM, Kaiser C, Huey WY, et al.: Efficacy and safety of an insulin infusion protocol in a surgical ICU. J Am Coll Surg 2006, 202:1-9.

23. Meijering S, Corstjens AM, Tulleken JE, Meertens JHJM, Zijlstra JG, Ligtenberg JJM: Toward a feasible algorithm for tight glycaemic control in critically ill patients: a systematic review of the literature. Crit Care 2006, I0:RI9.

24. Meade MO, Ely EW: Protocols to improve the care of critically ill pediatric and adult patients. JAMA 2002, 288:260I-2603.

25. Finney SJ, Zekveld C, Elia A, Evans TW: Glucose control and mortality in critically ill patients. JAMA 2003, 290:204I-2047.

26. Vriesendorp TM, DeVries JH, van Santen S, Moeniralam HS, de Jonge E, Roos YBWEM, Schultz MJ, Rosendaal FR, Hoekstra JBL: Evaluation of short-term consequences of hypoglycemia in an intensive care unit. Crit Care Med 2006, 34:27।4-27I8.

27. Finkielman JD, Oyen LJ, Afessa B: Agreement between bedside blood and plasma glucose measurement in the ICU setting. Chest 2005, I 27:|749-|75|.

\section{Pre-publication history}

The pre-publication history for this paper can be accessed here:

http://www.biomedcentral.com/1471-227X/7/14/pre pub
Publish with Biomed Central and every scientist can read your work free of charge

"BioMed Central will be the most significant development for disseminating the results of biomedical research in our lifetime. "

Sir Paul Nurse, Cancer Research UK

Your research papers will be:

- available free of charge to the entire biomedical community

- peer reviewed and published immediately upon acceptance

- cited in PubMed and archived on PubMed Central

- yours - you keep the copyright

Submit your manuscript here:

http://www.biomedcentral.com/info/publishing_adv.asp
BioMedcentral 